\title{
Vidas e Política das Pessoas Pobres - as coisas que um etnógrafo político sabe (e não sabe) após 15 anos de trabalho de campo ${ }^{1}$
}

JAUIER AUYERO"

\section{Resumo}

Ao refletir sobre uma década e meia de trabalho etnográfico, este artigo examina as lições aprendidas na tentativa de esquadrinhar as dinâmicas políticas entre pobres do meio urbano. O texto inicia com uma análise das limitações do conceito de clientelismo político buscando entender o que de fato ocorre quando votos são "trocados" por recursos. Segue examinando a relação recursiva entre patronagem e ação coletiva - dois fenômenos políticos geralmente vistos como mutuamente antagônicos. O artigo discorre então sobre a noção de "zona cinzenta" - como área de ligações clandestinas entre perpetradores de violência e autoridades políticas estabelecidas. O trabalho encerra com uma análise de dois temas que surpreendentemente têm estado ausentes na pesquisa sobre pobreza urbana - sofrimento ambiental e a política da espera.

Palavras-chave: Etnografia política. Ação coletiva. Clientelismo. Patronagem. Política dos pobres. Política da espera. Sofrimento ambiental.

1 Tradução de Regina Beatriz Vargas.

* PhD, The New School for Social Research. Professor de Sociologia Latino-americana, Cátedra Joe R. e Teresa Lozano Long. Departamento de Sociologia, Universidade do Texas, Austin, EUA. E-mail: auyero@austin.utexas.edu 


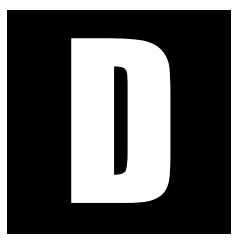

ecorrem 15 anos desde que iniciei meu primeiro projeto, mais ou menos sistemático e rigoroso, de trabalho de campo de longo prazo - aquele que culminou em meu primeiro livro (Auyero, 2000). Nesses 15 anos, conduzi (individualmente ou em cooperação com outros) quatro distintos projetos, de maior ou menor cunho etnográfico, e atualmente estou finalizando um quinto. Neste artigo, pretendo revisar as principais lições substantivas e analíticas aprendidas nas idas e vindas entre "estar lá" (no campo) e "estar aqui" (entre acadêmicos) - para fazer eco à famosa distinção de Clifford Geertz - e, também, destacar os desafios que ainda se colocam, propondo algumas vias para a pesquisa comparativa.

O clientelismo político, sua relação com a ação coletiva, o papel dos vínculos clandestinos na política, a marginalidade urbana e o sofrimento ambiental, a espera das pessoas pobres como forma de experimentar a dominação política: estes são os cinco tópicos (admito, muito amplos) que, em ordem cronológica, têm-me obcecado ao longo desses quinze anos. O que aprendi? Como penso que poderíamos melhorar nossas explicações sociológicas sobre estes temas?

\section{Clientelismo Político}

O clientelismo político tem sido uma das mais fortes e mais recorrentes imagens no estudo das práticas políticas dos pobres urbanos e rurais na América Latina; quase a ponto de se tornar uma espécie de "prisão metonímica" (Appadurai, 1988) para esta parte das Américas. Usada (e abusada) para explicar as razões porque as pessoas pobres e destituídas por vezes seguem líderes populistas - e, às vezes, aqueles autoritários ou conservadores -, a noção de clientelismo político tem sido entendida como um dos elementos mais centrais do apelo populista; mas tem tam- 
bém sido definida como um modo de inclusão política vertical, distinto do populismo. Além disso, o clientelismo político é constantemente associado às limitações das democracias sempre frágeis da América Latina. Ele é visto como um dos pilares da dominação oligárquica, que reforça e perpetua o domínio das elites políticas tradicionais, além de uma prática que permanece na essência do comportamento dos partidos. Com a ênfase neoliberal sobre os programas sociais 'direcionados', o clientelismo político tem sido descrito como um dos principais obstáculos que o Estado mínimo, hoje, precisa superar para alcançar os mais pobres entre os pobres.

Definido como a distribuição (ou promessa) de recursos por parte de políticos em exercício ou candidatos em troca de apoio político, o clientelismo tem exibido, para citar a perspicaz análise de Robert Merton das máquinas políticas nos Estados Unidos, "uma notável vitalidade" em várias partes do mundo moderno (1949, p.71). Nas palavras dos autores do mais recente levantamento sobre este resiliente fenômeno sociopolítico, o clientelismo é um tipo particular de vínculo partido-eleitor; é uma "transação, a troca direta do voto de um cidadão em troca de pagamentos ou de acesso continuado a emprego, bens e serviços" (Kitschelt e Wilkinson, 2007, p.2). Segundo estes autores, os vínculos eleitor-partido fundados em patronagem ainda operam (e, às vezes, se expandem) não apenas nas novas democracias da América Latina, na Europa pós-comunista, no sul e sudeste da Ásia e partes da África, mas também, ao contrário das previsões daqueles que viam no clientelismo "um resquício dos padrões pré-industriais, que iria desaparecer gradualmente no ocidente modernizante" (Kitschelt e Wilkinson, 2007, p.3), em muitas democracias industriais como Itália, Áustria e Japão².

2 Para uma evidência de sua persistência no México, ver também Holzner, 2007; Tosoni, 2007; no Brasil, ver Arias, 2006; na Argentina, ver Brusco, Nazareno e Stokes, 2004 e Levitsky, 2003; na Bolívia, ver Lazar, 2008; na Venezuela, ver Smilde, 2008; no Peru, ver Schneider e Zúniga-Hamlin, 2005; na Índia, ver Wilkinson, 2007; para um survey geral, ver Roniger e Günes-Ayata, 1994. 
Sabe-se que as trocas clientelistas se concatenam em redes piramidais constituídas por relações assimétricas, recíprocas e face-a-face. A estrutura do que David Knoke (1990) chama de "redes de dominação" e os atores chave dentro delas (patrões, mediadores e clientes) são fenômenos bem estudados da vida política popular tanto no meio urbano como no rural (para exemplos de trabalhos clássicos, ver Scott, 1977; Scott e Kerkvliet, 1977; para exemplos de trabalhos recentes ver Lazar, 2008; Auyero, 2007; Schedler, 2004; Holzner, 2004, 2007).

Um consenso na ampla literatura sobre o tema é o de que as relações patrão-mediador-cliente estão tão distantes de qualquer forma simmeliana de sociabilidade ("o tipo mais puro, mais transparente, mais atrativo de interação - aquela entre iguais" [Simmel, 1971, p.133]) quanto de uma societas leonina Romana (uma parceria na qual todos os benefícios ficam com uma parte). A vasta literatura converge na análise de que as relações clientelistas formam uma mistura complexa de quatro formas distintas de interação identificadas por Simmel em seu clássico On Individuality and Social Forms: troca, conflito, dominação e prostituição. As relações clientelistas são vistas como arranjos hierárquicos, como laços de dependência e controle baseados em diferenças de poder e na desigualdade. Por serem altamente seletivas, particularistas e difusas, elas são "caracterizadas pela troca simultânea de dois diferentes tipos de recursos e serviços: instrumentais (p.ex., econômicos e políticos) e de "sociação" ou expressivos (p.ex., promessas de lealdade e de solidariedade)" (Roniger, 1990, p.3; representantes da profusa literatura incluem Silverman, 1965; Guterbock, 1980; Bodeman, 1988; Gay, 1998).

Com seus favores particularizados, patrões e mediadores oferecem canais alternativos para uma pessoa "conseguir o que precisa" esquivando-se da indiferença burocrática. Como mostram de forma convincente Robert Gay (1990; 1994) e Gerrit Burgwald (1995) em seus estudos de 
duas favelas no Rio de Janeiro e de uma ocupação ilegal em Quito, a mediação clientelista é um meio efetivo de obter muitos serviços urbanos que, de outro modo, estariam indisponíveis para aqueles que não têm contatos. Com suas regras formais de promoção e recompensa (em uma estrutura partidária igualmente informal), e seu acesso de baixo custo a empregos públicos, a rede clientelista também oferece um dos poucos canais restantes de ascensão social. Em um contexto de oportunidades econômicas minguantes, o engajamento sustentado e fiel ao aparato partidário pode assegurar aos participantes o acesso a empregos e à influência na distribuição dos recursos públicos ${ }^{3}$.

A maioria dos estudos ainda enfoca o clientelismo como uma forma de obtenção de votos, uma forma de dominação política. Sem negar o fato de que esta prática política particular é útil (com suas limitações) como estratégia eleitoral, como uma forma de resolver problemas organizacionais do partido e como uma forma de poder político sobre populações despossuídas, penso que perdemos muito do "onde a ação está" - para citar Goffman - (ficando, assim, cegos quanto às razões pelas quais o clientelismo persiste e floresce), se não examinarmos a patronagem como uma estratégia dos pobres para solucionar problemas. Precisamos, e aqui reside uma das lições analíticas centrais que tentei exprimir em meu trabalho (e um ponto para futuro trabalho comparativo), mudar o foco de atenção nos estudos sobre o clientelismo político

3 Como registram Kitschelt e Wilkinson (2007, p.19), o clientelismo é normalmente realizado através de redes duradouras e multifacetadas de trocas recíprocas: "Em muitos sistemas caracterizados por níveis relativamente altos de pobreza - como Tailândia, Índia, Paquistão ou Zâmbia - os patrões compram diretamente os votos dos clientes em troca de dinheiro, bebidas, roupas, alimento ou outras mercadorias de consumo [...]. De modo muito mais frequente do que as transações únicas desta natureza, no entanto, estão as redes de troca, obrigação e reciprocidade sustentadas durante longos períodos, nas quais os patrões proporcionam bens privados e coletivos a seus clientes". 
e prestar muito mais atenção ao lugar que este arranjo político ocupa nas vidas da maioria dos destituídos. Quão importante é a patronagem como uma estratégia de solução de problemas em meio à pobreza urbana? Como ela compete (ou deixa de competir) com outras estratégias de solução de problemas (mercado, serviço social estatal etc.)? Sabemos que a patronagem é, para líderes e mediadores partidários, uma forma de comprar votos e/ou de comprar afluência às urnas (Stokes, 2005; Nichter, 2008). O que o clientelismo representa para os clientes? Testemunhos sobre as ações de clientelismo são normalmente coletados por políticos opositores, por jornalistas ou por líderes comunitários que se opõem a esse "modo de fazer política". Também "aprendemos" sobre a disseminação da patronagem através de pesquisas de opinião que raramente vão além da superfície da efetiva "troca de votos por favores" (Qual a sua opinião sobre clientelismo? Você ou seu vizinho alguma vez recebeu um favor de um político local em período de eleições?). Apenas esporadicamente alguém escuta os ditos 'clientes' sobre as razões que eles próprios atribuem ao seu comportamento (apoiar determinado patrão ou mediador, comparecer a comícios etc.), sobre sua opinião relativa ao que outros rotulam como procedimentos "antidemocráticos". As perspectivas dos clientes são cruciais para entender e explicar os fundamentos objetivos e subjetivos do clientelismo político, TANTO como um mecanismo de dominação política QUANTO como estratégia de solução de problemas entre os pobres urbanos. Outra lição analítica (e rota para futura pesquisa) que aprendi: precisamos trabalhar mais e melhor para reconstruir e explicar as perspectivas dos clientes.

A política de patronagem não se refere apenas à distribuição de recursos materiais em troca de apoio político. Uma linha de pesquisa inspirada pela sociologia de Pierre Bourdieu observou que o clientelismo não vive apenas na objetividade da rede de trocas, vive também, de forma 
subjetiva, nas disposições que inculca em alguns de seus atores - disposições que asseguram a reprodução desse arranjo (Rutten, 2007; Auyero, 2000; 2007). Essa pesquisa registra que o aparecimento automático da troca de "apoio por favores" observado com frequência na literatura, não deveria ser interpretado em termos mecanicistas, mas sim como resultado do habitus que gera em seus beneficiários ou clientes. Este corpus de pesquisa mostra que as atividades cotidianas das redes clientelistas de solução de problemas produzem um conjunto de disposições entre aqueles que recebem os favores diários de patrões e mediadores. Enfatizo a operação regular, rotineira, dessa rede, para destacar que essa relação transcende atos singulares de troca. Em sua análise da emergência do ativismo entre trabalhadores filipinos, Rutten (2007) rotula este instrumental de disposições de "habitus clientelista". Tais esquemas de percepção, avaliação e ação são, por sua vez, reconfirmados nas ações simbólicas rotineiramente formuladas por patrões e mediadores em seus discursos públicos (enfatizando o "amor" por seus partidários, sua "dedicação ao povo") e no modo personalizado de dar (destacando "seus" esforços para obter os bens e, assim, criando a imagem de que, se eles não estivessem lá, os benefícios não seriam entregues) ${ }^{4}$. Em outras palavras, a política clientelista não está limitada à solução de problemas materiais. O "estilo de dar" que mediadores e patrões expressam - um modo de dar em que o patrão e/ou mediador (seja ela ou ele um precint captain de Chicago, um cacique mexicano, um puntero argentino ou um cabo eleitoral brasileiro) se apresenta como "apenas um de nós, que sabe do que estamos falando" (Merton, 1949, p. 75) - é uma dimensão central no funcionamento e persistência da patronagem. O "modo humanizador e personalístico de assistir os necessitados", como Merton o coloca maravilhosamente, é,

4 Para uma análise dessa dimensão simbólica das redes de patronagem, ver Auyero (2000). 
portanto, um elemento constitutivo na operacionalização e na persistência do clientelismo. Há que produzir pesquisa muito mais minuciosa e sistemática sobre a formação e reprodução dos (e possíveis desafios aos) habitus clientelistas de clientes e de políticos.

Se alguma coisa aprendi, depois de três anos de trabalho de campo e de produção acadêmica, foi que a patronagem deve sua durabilidade à consolidação e normalização de dois (não um) tipos de práticas, em duas esferas (o campo político e a vida cotidiana dos pobres urbanos) distintas, mas (às vezes) entrelaçadas: a) a distribuição personalizada de bens e serviços por parte de políticos em busca de votos e/ou de participantes para a máquina política (inclusive, como veremos adiante, tropas de choque); b) a solução de problemas de sobrevivência pelas pessoas pobres através da criação e reprodução de relações duráveis com mediadores políticos (via voto, comparecimento a comícios, participação na máquina política, e/ou nas tropas de choque dos partidos). Mais, muito mais, precisa ser esmiuçado sobre o surgimento, o fortalecimento e a legitimação dessa forma de fazer política e esse modo de resolver problemas urgentes.

\section{Patronagem e Ação Coletiva}

Entre as descobertas mais consagradas na pesquisa sobre movimento social e ação coletiva, estão as noções de que "laços sociais prévios operam como uma base para o recrutamento na mobilização e que os espaços sociais estabelecidos são o locus para a emergência do movimento" (Diani e McAdam, 2003, p.7). O conhecimento acumulado converge sobre o papel fundamental desempenhado por organizações autóctones ou por redes associativas no surgimento de um movimento (McAdam 1982; Morris 1984; Osa 1997, 2003; McAdam, Tarrow, Tilly 2007). 
Longe de ser reino de possível cooperação, redes de patronagem são, ao contrário, consideradas estruturas (des)mobilizadoras (Rock, 1972, 1975; O'Donnell, 1992; Holzner, 2004). Brilhantemente conceptualizados por Julian Pitt-Rivers (1954, p.140) como "uma amizade desigual", os laços patrão-cliente são vistos como o oposto exato das redes horizontais de engajamento cívico, das quais se diz que fomentam uma verdadeira comunidade cívica e que, por sua vez, "fazem funcionar a democracia" (Putnam et al., 1993) e tornam possível a ação do movimento social. A inserção em relações clientelistas é vista como um supressor da participação nos contextos relacionais mais horizontais, que têm sido identificados como "propícios a várias formas de engajamento coletivo" (Diani e McAdam, 2003, p. 2; ver também Emirbayer e Goodwin, 1994; Oliver, 1984; McAdam e Fernandez, 1990; Taylor e Whittier, 1995; Passy, 2003; Mische, 2003).

Pesquisas conduzidas em enclaves urbanos de pobreza (favelas, ocupações ilegais, colonias etc.) e junto a movimentos de pessoas pobres na América Latina têm mostrado que a patronagem e a mobilização coletiva podem, na verdade, coexistir no mesmo espaço geográfico; geralmente de forma conflituosa (Gay, 1990; Burgwald, 1995; Lazar, 2008). Em sua crônica da eclosão e desenvolvimento do movimento piquetero na Argentina (como o movimento social que reuniu os desempregados e que utilizou bloqueio de vias, piquetes, como tática principal), Svampa e Pereyra (2003, p.93), por exemplo, afirmam que as organizações de piqueteiros representam um "primeiro desafio concreto aos punteros (mediadores políticos)" da máquina clientelista do partido peronista (grifo meu). Outro exemplo recente pode ser encontrado no trabalho de Claudio Holzner (2004). Ao escrever sobre a "obstinada resiliência de organizações e práticas clientelistas no México, inobstante uma sociedade civil cada vez mais fortalecida e a crescente competição eleitoral em todos os níveis" (p. 77), ele observa a emergência de formas "rivais" de organização política - uma hierárquica e 
clientelista e outra que enfatiza a participação democrática e a autonomia política e que "resiste ativamente ao clientelismo político" (p.77, grifo meu).

Embora apontando a complexidade da política dos pobres e a diversidade das estratégias de solução de problemas utilizadas pelos destituídos, todos esses estudos descrevem redes clientelistas e de mobilização como dois campos distintos e opostos de ação política, duas esferas de interação social e de trocas que quase nunca coincidem e que normalmente "rivalizam", "resistem" ou "desafiam-se" mutuamente ${ }^{5}$. A pesquisa existente concorda que a supremacia da política de patronagem entre os pobres frustra a formulação de demandas coletivas, além de isolar e atomizar os cidadãos, impedindo, desse modo, o trabalho organizacional e relacional que constitui a base da ação coletiva.

Mas a literatura também admite que, em um caso particular (aquele da ruptura dos acordos clientelistas), o protesto pode, na verdade, eclodir da patronagem - e o faz, normalmente, de modo explosivo. Quando um sistema fluente de relações patrão-cliente que são fundamentais para a sobrevivência da população local deixa de cumprir compromissos ou se desfaz subitamente, a "reciprocidade se transforma [pode transformar-se] em rivalidade" (Lemarchand, 1981, p.10). Os pesquisadores estão familiarizados com essas situações de mobilização de massa que se originam de falhas abruptas na rotina social e nas relações políticas: o cientista político James Scott (1977) estudou uma dessas ocorrências ao escrever sobre revoltas coletivas provocadas por mudanças bruscas no "equilíbrio da reciprocidade" entre proprietários de terra e arrendatários (equilíbrio que, como Scott examinou em detalhes, constituiu o fundamento normativo das redes clientelistas em sociedades agrárias). O historiador E. P. Thompson

5 Para uma recente e esclarecedora exceção às formas pelas quais cidadãos, em sua tentativa de resolver problemas prementes de sobrevivência, podem transitar entre redes "oponentes", ver Quiros (2008). 
(1993) desvendou um caso análogo em sua descrição minuciosa das revoltas por alimentos, na Inglaterra do século 18, como manifestações de ruptura da "economia moral dos pobres" - da "sistemática visão tradicional de normas e obrigações sociais, das funções econômicas próprias aos diversos grupos na comunidade" (Thompson, 1993, p.188). Uma afronta a essas premissas morais, causada por uma inesperada alteração no "particular equilíbrio entre a autoridade paternalista e o povo" (p.249), foi, na perspectiva de Thompson, "a ocasião usual para a ação direta"6.

A maior parte da investigação sobre redes de patronagem aponta para seu potencial mau funcionamento enquanto geradoras de protestos repentinos que, por sua vez, criam a oportunidade para ação coletiva ${ }^{7}$. Apenas mais recentemente, redes clientelistas que funcionam bem têm sido analisadas como apoios relacionais cruciais para a ação coletiva. Nestes estudos, as redes verticais não precisam ser rompidas para que a ação coletiva possa emergir; alguns de seus atores chave (patrões, mediadores e/ou clientes) podem, por uma série de razões (que vão de ameaças aos acordos vigentes a tentativas de melhorar sua posição no campo político) tornam-se organizadores da ação coletiva (e, em alguns casos, violenta).

Estudiosos de guerras civis mostram, por exemplo, que disputas entre redes clientelistas ativas podem estar na base do confronto violento. Ao escrever sobre os homicídios em massa que tiveram lugar na Indonésia entre 1965 e 1966, Stathis Kalyvas (2003, p.478) afirma que, ainda que

6 Mais recentemente, a socióloga Magdalena Tosoni (2007) disseca outra ocorrência ao focar sua atenção sobre o México urbano contemporâneo. Ela descreve o processo através do qual residentes da colonia San Lázaro (uma zona de classe trabalhadora da cidade do México) fizeram campanha, apoiaram e votaram em um candidato que havia prometido ajudá-los a resolver um problema de posse de terras naquele distrito. Ao assumir o cargo, o político "esqueceu" seus clientes e não cumpriu o acordo. Em razão disso, a comunidade se mobilizou, realizando uma grande manifestação e bloqueio de vias.

7 Sobre a natureza variável dos protestos como um importante fator de mobilização, ver Walsh (1981). 
eles tenham sido "evidentemente articulados em torno da oposição comunismo/anticomunismo... [U]m exame prolongado dos massacres regionais trouxe à luz todo o tipo de conflitos locais... [E]m Bali, eles estavam associados a antigas rivalidades entre grupos de patronagem". Redes de patronagem também têm sido identificadas como o apoio relacional crucial da violência coletiva na Colômbia. Como argumenta Steffen Schmidt (1974, p. 109): "A violência política da Colômbia (...) é devida, em grande parte, à existência da uma política competitiva, agressiva e disseminada, baseada em relações patrão-cliente".

Mas a relação entre patronagem e conflitos não necessariamente assume uma forma violenta. Em seu estudo sobre protestos ambientais em oito comunidades no sul do Japão, Broadbent (1998; 2003) observa a presença do que ele chama "chefes dissidentes" (isto é, líderes locais que se unem aos contestadores). Na análise de Broadbent, esses chefes são indicativos da existência de laços verticais entre cidadãos e elites que moldam as oportunidades políticas locais. Os chefes políticos locais, diz ele, "formaram uma estrutura vertical de controle social, [a qual] penetrou na comunidade através do partido político, do governo e de grandes empresas" (pp. 219-220). Assim como um precint captain nas máquinas políticas de Chicago analisadas por Guterbock (1980), ou um cabo eleitoral em uma favela brasileira (Gay, 1990), esses chefes locais constroem seu poder na comunidade via patronagem - isto é, "oferecendo generosas contribuições para funerais e casamentos, promovendo festas para construir laços de camaradagem, distribuindo propinas em época de eleição, conseguindo empregos e até potenciais casamentos" (Broadbent, 2003, p.222). Redes de patronagem colocam "uma formidável barreira à mobilização, no contexto de uma comunidade" (2003, p. 223), a menos que um chefe dissidente se desvincule: "uma vez que um chefe tradicional rompeu com seus chefes em favor da resistência, ele é capaz de carregar 
'automaticamente' (estruturalmente) muitas de suas redes subordinadas para o movimento de protesto" (p. 221).

Assim, mais do que duas esferas opostas de ação ou duas distintas formas de sociabilidade, patronagem e política de contestação podem estar mutuamente imbricadas. Independentemente de funcionar mal ou de prosperar, o clientelismo pode estar na raiz da ação coletiva - uma incorporação que estudos de uma série de conflitos anteciparam, mas não lograram explorar em detalhes (Tilly, 1986; 1995; 2006).

A evidência disponível sobre o que eu chamo de cenário de apoio é limitada e dispersa, por uma razão. Esta forma de relação recursiva entre patronagem e ação coletiva não tem sido examinada em profundidade, seja teórica ou empiricamente. Não é necessário um colapso ou uma interrupção no fluxo das trocas clientelistas, para que o conflito ocorra. Redes de patronagem que funcionam bem podem ser ativadas deliberadamente para conduzir a ação política por outros meios coletivos (às vezes violentos). É preciso muito mais trabalho empírico e teórico sobre as várias formas de imbricação entre patronagem e contestação. A desatenção à relação recursiva entre os dois fenômenos pode levar à não percepção de boa parte das dinâmicas da política popular, tanto nas formas rotineiras quanto nas extraordinárias. Um foco empírico sobre a área em que elas se encontram e enredam permitiria uma melhor perspectiva de dois processos que têm sido identificados como cruciais em muitas formas de política de contestação. Estes dois processos são intermediação - aqui entendida simplesmente como "a formação de vínculos sociais entre pessoas e lugares antes desconectados" (Burt, 2005) - e certificação - aqui entendida como "a validação de atores, de suas performances e de suas demandas, por parte de autoridades externas" (McAdam, Tarrow e Tilly, 2001; ver também Tarrow e Tilly, 2007; McAdam, Tarrow e Tilly, 2008). Uma área de pesquisa especialmente desafiante sobre este tópico é aquela que foca o que eu chamo de "zona cinzenta" da política popular. 


\section{A Zona Cinzenta}

A evidência empírica cresce e torna-se (cada vez mais) inequívoca. O que Charles Tilly (2003) chama de "especialistas da violência" - isto é, atores que se especializam em infligir dano físico - joga um papel central, ainda que às vezes não muito discernível, na origem e no curso da violência coletiva. Alguns desses especialistas (policiais e soldados, por exemplo) formam parte do aparato do Estado; outros (digamos, malfeitores, gangues, seguranças privados), no entanto, usufruem de ligações importantes, ainda que, muitas vezes, clandestinas com os detentores de poder. Esses "laços obscuros" entre atores estatais e perpetradores de violência definem aquilo que, em trabalho anterior (Auyero, 2007), eu chamei de "a zona cinzenta da política" e colocam em questão as distinções apressadas e simplistas entre Estado e sociedade que a maior parte da literatura sobre ação coletiva ainda toma como dadas (entre agentes governamentais, forças de segurança, contestadores, membros do sistema político etc.).

Ainda que longe de ser uma área de pesquisa claramente delimitada, a relação entre conexões políticas clandestinas e violência coletiva tem sido tema de crescente interesse acadêmico. Por exemplo, a pesquisa sobre as origens e as formas de violência comunitária no sudeste da Ásia evidenciou os vínculos ocultos entre a política partidária e a violência coletiva (Das, 1990). O conceito de Paul Brass, de "sistemas de revolta institucionalizada", descreve de forma pertinente essas conexões obscuras. Nestes sistemas de revoltas, observa Brass, "atores conhecidos se especializam na conversão de incidentes entre membros de diferentes comunidades em conflitos étnicos. As atividades desses especialistas, que operam sob um fraco controle de líderes de partidos, são normalmente necessárias para que uma revolta se propague a partir de uma provocação inicial" (Brass, 1997, p. 12). A análise de Sudhir Kakar (1996), de um peh/wan, um lutador/segurança que trabalha para um líder político, ilustra 
melhor este ponto: a gênese de muitos episódios de violência coletiva está localizada na região em que as atividades dos atores políticos e daqueles especialistas em violência se entrelaçam secretamente.

Votes and Violence, de Steven Wilkinson (2004), é possivelmente o estudo mais sistemático feito até hoje sobre as conexões entre partidos políticos (disputas eleitorais) e violência coletiva (conflitos étnicos). WiIkinson mostra, de forma contundente, que:

Conflitos étnicos, longe de ser eclosões de ódio relativamente espontâneas, são frequentemente planejadas por políticos com um claro propósito eleitoral. Será mais adequado considerá-los como uma solução para o problema de como transformar a proeminência de questões éticas e de identidades entre o eleitorado, de modo a construir uma coalizão política vencedora (p. 1).

Ao longo de todo seu perspicaz e detalhado estudo, Wilkinson chama a atenção para os episódios em que as elites políticas "provocam", "fomentam", ou "instigam" revoltas "para vencer eleições" (p. 236) e coloca em relevo o que, muitas vezes, se configura como cumplicidade do Estado em deixar de prevenir a violência. A resposta do Estado, argumenta, está muito condicionada pelas "instruções" que os políticos dão a outros agentes estatais sobre "proteger ou não algumas minorias" (pp. 65 e 85). As elites e organizadores políticos frequentemente "incitam" a violência e impedem as forças de segurança de reagirem quando estoura a revolta. Por quê? As conclusões de Wilkinson são claras. Os líderes políticos, em alguns estados indianos, "inculcam, em seus dirigentes locais, que revoltas comunitárias e massacres (pogroms) devem ser evitados a qualquer custo" (p.137) devido a incentivos eleitorais.

Relatos históricos de "revoltas raciais" nos Estados Unidos também apontam para uma dinâmica similar entre membros dos partidos políticos oficiais e na instigação (ou não) da violência coletiva. Janet Abu-Lughod (2007), por exemplo, documenta os ataques cometidos pelos Ragen's 
Colts - jovens assessores partidários que eram apoiados financeiramente por Frank Ragen, um conhecido comissário de polícia do Condado de Cook (Illinois) - contra afro-americanos, durante os conflitos de 1919, em Chicago. Anos mais tarde, durante os conflitos de 1943, em Detroit, brancos que atacavam negros podiam contar "com a proteção e até mesmo com ajuda policial" (2007, p. 148).

Que líderes de partido e/ou autoridades governamentais possam estar "detrás" - em vez de contra - tais episódios de violência coletiva não deveria surpreender estudantes de política latino-americana. Em um estudo detalhado de la violencia - a onda de violência política que matou 200 mil pessoas na Colômbia nas décadas de 1940 e 1950 - a historiadora Mary Roldán mostra que, no estado de Antioquía, "conflitos partidários serviram como catalisadores da violência" (2002, p.22). Roldán argumenta que não só os burocratas do Estado "promoveram" a violência que abalou a região, como também a polícia e mesmo os próprios prefeitos participaram ativamente dos ataques. As elites políticas, ela observa, não somente toleraram ou instigaram a violência; foram suas perpetradoras. Enquanto membros de partidos organizavam ataques a locais e a pessoas, a polícia atuava como tropa de choque do partido. Com palavras que devem soar verdadeiras para quem estuda violência política em outras partes do mundo, Roldán afirma que: "enquanto muitos cidadãos atribuíam a escalada da violência à ausência de forças de segurança, essas forças foram com tanta frequência os perpetradores da violência, entre 1946 e 1949, que nos leva a imaginar por que alguém sugeriria que a presença de autoridades pudesse ajudar" (Roldán, 2002, p. 82). Laços clandestinos - revela Roldán - sobrevivem a episódios específicos de violência e apresentam características duráveis, estruturais.

A historiadora Laurie Gunst (1995) e o sociólogo Orlando Patterson (2001) trazem à luz as relações entre as redes locais de patronagem na Jamaica, ou o que Patterson chama "eleitorado fortificado" (garrison cons- 
tituency), e a violência de gangues. Patterson observa como essas gangues, que eram "inicialmente formadas para propósito políticos, agora servem também ao comércio de drogas... [e têm] atuado cada vez mais para gerar distúrbios como uma tática política". Gunst, por sua vez, argumenta que as origens das quadrilhas de traficantes jamaicanos em Nova York podem ser localizadas nesses mesmos grupos, originados na Jamaica, que foram armados por membros do partido, ligados aos Primeiros Ministros Seaga ou Manley. As etnografias recentes de Goldstein (2003) e de Arias (2006), das favelas do Rio de Janeiro, fornecem mais evidências da conivência entre atores estatais, membros de partidos políticos e promotores de violência como membros de gangues vinculadas ao tráfico de drogas. Finalmente, a reconstrução histórica feita por Luis Astorga (2005), do entrelaçamento do campo político com o campo da produção ilícita e do tráfico de drogas no México do século 20, aporta outro excelente exemplo das conexões (ocultas e muitas vezes ilegais) entre atores internos e externos ao sistema político oficial - relações que precisam ser rigorosamente examinadas, se quisermos explicar recrudescimentos aparentemente aleatórios da violência - tanto no passado como no presente.

O que todos esses casos têm em comum? Todos eles retratam a ativação de conexões clandestinas entre atores políticos bem estabelecidos no sistema político e outros situados fora deste. Ao confrontar-nos com "questões obscuras" (gray matters), a maior parte das categorias com as quais nós, pesquisadores da ação coletiva, operamos usualmente (categorias que são em boa medida informadas por análises empíricas realizadas nos Estados Unidos e na Europa) se revela inútil, quando não enganosa. Por mais que a literatura concorde que as interações entre elites políticas, agentes de controle social e protagonistas da desordem civil sejam importantes, estas continuam sendo entidades discretas. O imaginário acadêmico da antropologia política dos movimentos sociais e da ação coletiva situa-se em um mundo no qual existem fronteiras bem definidas entre 
insurgentes e autoridades, dissidentes ou contestadores e agentes do Estado, localizados em distintas regiões do espaço social e político (tais como o "lado da contestação" e o "lado da repressão"). Há um silêncio quase completo sobre a possível participação de autoridades (sejam representantes eleitos ou agentes de polícia) na promoção direta de mobilização e/ou diretamente na perpetração da violência coletiva. Em parte, a noção de zona cinzenta da clandestinidade busca abordar este problema, chamando a atenção para as continuidades entre ações do estado, rotinas políticas e violência em massa excepcional.

Os analistas políticos devem esforçar-se mais para integrar as relações de "zona cinzenta" aos estudos da política "normal". A desatenção a essas conexões clandestinas tem efeitos análogos à desatenção relativa às "instituições informais" observadas pelos cientistas políticos Gretchen Helmke e Steven Levitsky. Em ambos os casos, a análise política "corre o risco de não perceber boa parte daquilo que orienta o comportamento político e pode minar os esforços voltados a explicar importantes fenômenos políticos" (Helmke e Levitsky, 2004, p. 725). Ao invés de descartá-los como fenômenos anômalos ou de denunciá-los por razões moralistas, o desafio para uma análise propriamente científica é colocar em relevo em nossos modelos padrão de ação política estas relações geralmente sólidas; uma integração analítica que deve, por sua vez, permitir-nos incorporar de modo mais adequado a violência ao estudo da política popular, algo que, como dizia Charles Tilly, a maior parte da análise política ainda ignora. Resta muito trabalho (teórico e empírico) a ser feito.

\section{Sofrimento ambiental}

A pesquisa de campo sobre clientelismo, ação coletiva contenciosa e política de zona cinzenta levou-me a algumas das mais relegadas, destituídas, zonas de meu país de origem, a Argentina: bairros pobres, 
ocupações ilegais e favelas. Durante os vários anos em que parei em esquinas para falar com jovens, conversei com moradores em suas casas, os acompanhei a reuniões e comícios de partidos, brinquei com crianças em seus quintais, uma coisa que nunca (até bem pouco tempo) me chamara a atenção foi o ambiente físico deplorável em que vivem essas pessoas.

O "chão real da história" [dos pobres] - para usar a expressão de Karl Marx - permanece uma preocupação marginal entre os estudiosos da pobreza na América Latina, apesar de constar de parte da literatura existente sobre problemas ambientais urbanos (Lemos, 1998; Pezzoli, 2000; Evans, 2002; Hochstetler e Keck, 2007). Nem a recente e ampla revisão de estudos sobre a pobreza e a desigualdade na América Latina (Hoffman e Centeno, 2003), nem um simpósio sobre a história e o estado dos estudos sobre marginalidade e exclusão na América Latina (González de la Rocha et al., 2004) faz menção aos fatores ambientais como determinantes cruciais na reprodução da pobreza extrema e da desigualdade.

Com poucas e notáveis exceções (Scheper-Hughes, 1994; Paley, 2001; Farmer, 2003), as etnografias da pobreza urbana e da marginalidade na América Latina também têm sido omissas em relatar o simples fato de que os pobres não respiram o mesmo ar, bebem a mesma água ou brincam nos mesmos parques que os outros. As vidas das pessoas pobres não se desenrolam na cabeça de um alfinete*. O seu é um ambiente frequentemente poluído, que afeta de modo sério sua saúde presente e suas capacidades futuras, e sobre o qual os pesquisadores, entre os quais me incluo, têm guardado silêncio por muito tempo. Este silêncio (outra encarnação do que Sherry Ortner (1995) genialmente chamou de "recusa etnográfica") é espantoso, dado o lugar destacado do contexto material

\footnotetext{
* NT1: Referência a uma questão que teria sido originalmente formulada por São Tomás de Aquino "Poderiam vários anjos dançar sobre a cabeça de um alfinete?" - referindo-se à natureza e à não corporeidade dos anjos.
} 
das vidas dos pobres tanto em um texto fundador no estudo da pobreza e da desigualdade, A situação da classe trabalhadora na Inglaterra, de Friedrich Engels, como em um dos textos seminais sobre as vidas dos párias urbanos nas cidades latino-americanas. Em Quarto de Despejo - Diário de uma favelada*, Carolina Maria de Jesus (2003), moradora de uma favela na cidade de São Paulo, Brasil, durante a década de 1950, fornece um relato em primeira mão da vida cotidiana nesse espaço. Carolina se refere a sua favela com palavras que parecerão dolorosamente familiares aos habitantes de bairros pobres em toda a América Latina e em muitas outras partes do Terceiro Mundo: "é um depósito de lixo", ela escreve. "Para viver num lugar assim, só porcos. Isto aqui é o chiqueiro de São Paulo" (p.27). Ao longo de todo o livro, ela menciona águas poluídas e o que chama de "perfume" de "lama podre (e) excremento" (p.40) ao definir as características da vida nos enclaves de pobreza. Meio século depois, a favela continua envolta pelo mau cheiro e por terras e águas contaminadas.

Que significado as pessoas pobres atribuem ao perigo tóxico (e como lidam com ele)? Quando e por que elas não entendem (e não reagem a) o que objetivamente é um perigo atual e evidente? Como, e por quê, percepções (errôneas) são partilhadas em uma comunidade? Estas foram as questões gerais que me levaram a Flammable, uma favela cercada por um dos maiores complexos petrolíferos da Argentina (local da única refinaria de petróleo que a Shell possui na América Latina), por um rio altamente poluído que carrega os resíduos tóxicos de curtumes e de outras indústrias, por um nocivo (e pouco controlado) incinerador de lixo, e por um aterro sanitário também não controlado.

\footnotetext{
* NT2: Publicado pela primeira vez no Brasil em 1960, foi traduzido para 14 idiomas (cfe. Perpétua, E.D. Produção e Recepção de Quarto de Despejo,de Carolina Maria de Jesus: Relações Publicitárias, Contextuais e Editoriais. In: Em Tese. Belo Horizonte, v. 5, p. 33-42, dez. 2002). Nos EUA foi publicado com o título Child of the Dark. The Diary of Carolina Maria de Jesus.
} 
O que testemunhamos em Flammable é, como propusemos em nosso trabalho conjunto (Auyero e Swistun, 2009), a desigualdade perene em produção; uma desigualdade que está sendo criada não em torno da dimensão mais comumente estudada (salários) (Tilly, 1998), mas em torno da relação entre meio ambiente e saúde. Reiterando, esta é uma faceta crucial para o bem-estar da população, mas que tem sido tradicionalmente negligenciada nos estudos sobre as persistentes iniquidades na América Latina.

A lição que emerge daquele estudo de caso para os estudiosos da pobreza e da desigualdade de classe em todo o mundo é a seguinte: qualquer esboço sociológico da marginalidade urbana e de seus efeitos sobre a privação socialmente organizada deve dedicar atenção empírica contínua e sistemática ao ambiente contaminado e/ou nocivo, em maior ou menor medida, onde vivem os pobres urbanos. É crucial colocar a (in)justiça ambiental no centro das análises da pobreza. Juntamente com renda, emprego, educação e outras variáveis convencionais, as análises sociológicas das causas e manifestações da privação urbana devem levar em conta a exposição diferenciada dos pobres aos riscos ambientais. A marginalidade é, para parafrasear a geógrafa Doreen Massey (1994), construída espacialmente; e tal espaço é carregado de poluição e riscos em maior ou menor grau. Esta organização espacial da marginalidade faz uma diferença na forma como ela funciona e como é experimentada. Em outras palavras, dado que viver em constante perigo e sob implacável agressão tóxica deixa, por vezes, marcas indeléveis nas mentes e nos corpos das pessoas pobres, a pesquisa urbana necessita urgentemente de uma geografia social do perigo e do sofrimento ambiental.

Em um dos últimos capítulos de Flammable, utilizamos a imagem mítica de Tirésias $^{8}$ para descrever uma das características que definem

8 Em uma das diversas versões do mito grego, Tirésias muito jovem surpreende Atena enquanto ela se banhava. Como punição por ele ter visto sua filha despida, Zeus cega o jovem Tirésias, mas o compensa com o dom da vidência. 
a vida os moradores daquela favela localizada em uma região altamente contaminada. Como o vidente grego, eles são forçados a tornarem-se "meros expectadores de acontecimentos que estão além do seu controle" (Schutz, 1964, p. 280). Moradores da favela estão sempre a esperar que algo aconteça. Intoxicados e excluídos, eles vivem em um tempo orientado para agentes poderosos e manipulado por estes. Eles vivem em um tempo alienado e são obrigados, como coloca de forma eloquente Pierre Bourdieu (2000, p. 237), "a esperar tudo dos outros". A dominação funciona - argumentamos - pela rendição ao poder de outros; e é experimentada como um tempo de espera: esperar com esperança, seguida de frustração, que outros tomem as decisões e, efetivamente, render-se à autoridade de outros. De formas inesperadas, encontramos muitas versões do conto de Tirésias entre habitantes contemporâneos da favela.

Ao dar os retoques finais no manuscrito, percebi que, ainda que a relação específica e algo extrema entre tempo, comportamento e submissão lá analisada seja peculiar a Flammable, esta dinâmica pode ser aplicável a muitas das populações subalternas que tenho estado pesquisando durante anos. Daí meu recente interesse na espera dos pobres.

\section{Espera}

Espera, escreve Pierre Bourdieu em Meditações Pascalianas, é uma das formas de experimentar os efeitos do poder. "Fazer esperar... protelar, sem destruir a esperança,... postergar, mas sem decepcionar de todo" são, segundo Bourdieu (2000, p. 227), partes integrantes do exercício de dominação. Ainda que os vínculos entre poder e tempo tenham sido meticulosamente examinados nas ciências sociais, a espera (tanto como uma região temporal quanto como uma atividade com intrincadas relações com a constituição e reprodução da submissão) permanece "escassamente ma- 
peada e mal documentada" (Schweizer, 2008, p.1). É compreensível, então, que: a atenção ao tema da espera e sua respectiva (aparente) inação contraria o foco preferencial das ciências sociais, colocado sobre a ação individual e coletiva, o evento - enquanto aquele "fato histórico que deixa um traço exclusivo e singular, um que marca a história por suas consequências especiais e inimitáveis" (Drumoulins, citado em Tarrow, 1996, p. 587).

Ao escrever justamente sobre esta ausência, Pierre Bourdieu (2000, p.228) afirma que precisamos "arrolar e submeter à análise todas as condutas associadas ao exercício de um poder sobre o tempo dos outros, quer do lado do poderoso (adiar para mais tarde, fazer esperar, atrasar, criar falsas esperanças ou, ao contrário, precipitar, surpreender) como de parte do 'paciente', como dizem no universo médico, um dos espaços por excelência da espera ansiosa, impotente". Apoiado em dezoito meses de etnografia comparativa no campo, meu projeto atual busca criar uma tempografia da dominação - isto é, uma descrição densa das formas pelas quais os dominados percebem a temporalidade e a espera.

Os múltiplos modos pelos quais os seres humanos, em seus mundos da vida, pensam e sentem (e agem sobre) o tempo têm sido objeto de intenso trabalho acadêmico nas ciências sociais - de abordagens gerais (Sorokin e Merton, 1937; Hall, 1959; Schutz, 1964; Durkheim, 1965; Giddens, 1986; Munn, 1992; Levine, 1997; Flaherty, 1999) àquelas mais empiricamente informadas, muitas delas baseadas em trabalho etnográfico (Roth, 1963; Mann, 1969; Geertz, 1973; Zerubavel, 1979; Young, 2002; Flaherty, Freiding e Sautu, 2005). As relações entre o funcionamento do poder (Lukes, 2005) e a experiência do tempo têm também sido objeto de diversas análises sociológicas. O tempo, por exemplo, tem sido estudado como uma dimensão crucial do funcionamento de trocas de dons (Bourdieu, 1977) e na operacionalização das redes de patronagem (Scott e Kerkvliet, 1977). Em ambos os casos, a verdade objetiva dessas 
trocas (geralmente desiguais) precisa ser desconhecida para que elas possam funcionar sem problemas (Bourdieu, 1998; Ortner, 1995). O tempo - demonstram essas análises - é responsável pela ocultação.

A temporalidade, como trabalhos históricos e etnográficos ilustram, é manipulável. Ela pode ser objeto de um "contínuo processo de barganha", como mostra Julius Roth (1963) em sua perspicaz etnografia das formas pelas quais pacientes e médicos conjuntamente estruturam a passagem do tempo em um hospital para tuberculose; ela pode ser objeto de "monitoração" desesperada, como apontam Stanley Cohen e Laurie Taylor em sua fenomenologia da ala de segurança de uma prisão inglesa (1972). O tempo também pode ser alvo de ataque constante, como ilustra Paul Willis (1977) em sua minuciosa análise da rejeição pelos jovens do horário arduamente construído pela escola; ou do meio pelo qual a disciplina é imposta e negociada, como demonstra E. P. Thompson (1994) em sua clássica análise das mudanças nas notações internas de tempo nos primeiros estágios do capitalismo industrial. As percepções coletivas do tempo estão profundamente entrelaçadas com o funcionamento da (e resistência à) dominação social. Esses trabalhos revelam que o tempo é o locus do conflito, mas é também, com igual relevância, o do consentimento (ver também Hochschild, 2001; Thompson e Bunderson, 2001; Jacobs e Gerson, 2005; Purser, 2006).

A espera, como um modo particular de experienciar o tempo, não tem recebido o mesmo interesse acadêmico. Enfatizando a ubiquidade desta experiência, a ensaísta Edna O’Brien escreve: “Todos os que conheço estão esperando". Insinuando o sentido de impotência que vem com a espera, ela segue: "e quase todos que conheço gostariam de rejeitar isto, pois é um pouco degradante, recende a desamparo, e mostra que não estamos em pleno comando de nós mesmos". Segundo O'Brien, a espera não afeta todos da mesma maneira - nem é experimentada de modo similar. O sociólogo Barry Schwartz é, provavelmente, quem mais 
fez para mostrar que essa espera é estratificada, que o tempo de espera apresenta variações, as quais são socialmente padronizadas e respondem a diferenças de poder. A distribuição desigual do tempo de espera tende a uma correspondência com aquela do poder (Schwartz, 1974; 1975). Segundo Schwartz (1974, p.856), ser submetido à espera, "sobretudo, ser submetido a uma espera excepcionalmente longa, é ser alvo de uma afirmação de que seu próprio tempo (e portanto seu prestígio social) é menos valioso do que o tempo e o prestígio daquele que impõe a espera" (sobre os efeitos degradantes da espera, ver também Comfort, 2008). O hoje clássico livro de Schwartz estabeleceu o arcabouço para uma análise sociológica da espera. Contudo, desde então, as experiências distintivas daquele (desigualmente distribuído) tempo de espera (e das atividades que, aparências em contrário, vão com ele) têm recebido pouca atenção empírica e nenhum tratamento sistemático.

A escassa pesquisa sobre o tema mostra que períodos de espera prolongados "cansam as pessoas" (Piven e Cloward, 1971, p. 160) e/ou agem como um obstáculo para acessar determinados programas (Redko, Rapp e Carlson, 2006). Se o contato frequente com longas filas molda as subjetividades das pessoas (Comfort, 2008), como é que, citando Bourdieu (2000, p. 228), a "mira interessada em uma coisa altamente desejada - ou seja, durante todo o tempo em que dura a expectativa - modifica a conduta daquele que está, como se diz, em suspenso pela decisão esperada"? Se as demoras não são apenas sofridas, mas também interpretadas (Schwartz, 1975), que significados aqueles que são rotineiramente forçados a esperar atribuem à espera? $\mathrm{E}$, se a espera faz aquele que espera sentir-se "dependente e subordinado" (Schwartz, 1975, p. 856), como o fato de esperar produz esses efeitos subjetivos de dependência e subordinação? Em outras palavras, como a espera objetiva se torna submissão subjetiva? Estas são as questões gerais que orientaram minha etnografia 
comparativa em três distintos locais onde os pobres urbanos aguardam decisões de agentes do Estado: a sala de espera do principal serviço social da cidade de Buenos Aires (Ministerio de Desarrollo Social), a fila na parte externa do RENAPER (Registro Nacional de las Personas), na qual imigrantes legais aguardam para solicitar seus documentos de identidade (Documento Nacional de Identidad), e Flammable, a favela em que recentemente conduzi uma revisita etnográfica.

Quais serão as maiores implicações do estudo proposto? Desta etnografia comparativa, elas são tanto analíticas como substantivas. Mais especialmente, meu trabalho atual une-se ao chamado por uma análise relacional dos processos políticos (Tilly, 1995; Heller e Evans, 2010), focando o envolvimento diário do Estado com os pobres urbanos. A relação entre os sujeitos destituídos e o Estado é de relevância analítica e teórica, porque é uma característica definidora do caráter efetivo da cidadania e do funcionamento da democracia (e do impacto desta última sobre a desigualdade) (Tilly, 2006; 2007).

Minha etnografia comparativa também possui implicações substantivas. Apesar da globalização econômica e da hegemonia neoliberal, o Estado - reduzido, descentralizado e/ou "esvaziado" (Steinmetz, 1999; Jessop, 1999) - segue sendo um ator fundamental nas vidas dos destituídos. Mesmo funcionando mal e escasso de recursos básicos, o Estado Argentino ainda concede acesso à cidadania e provê benefícios sociais (limitados, mas vitais). Está, em outras palavras, profundamente "implicado na textura mínima da vida cotidiana" dos pobres (Gupta, 1995, p. 375). São necessários mais e melhores trabalhos sobre o cenário das práticas relacionais que ligam as formas diárias de operação do Estado com as vidas dos subordinados sob regimes neoliberais. Por conferirem "concretude e forma ao que, de outro modo, seria uma abstração ('o Estado')" (Gupta, 1995, p.378), os encontros diários com as burocracias estatais são o ingrediente chave na 
rotina de construção do Estado e na padronização das relações de classe (Haney, 1996; Gupta, 2005; Secor, 2007). O Estado é, desse modo, tanto uma estrutura abstrata, de nível macro, como um conjunto concreto, microestrutural, de instituições com as quais os pobres urbanos interagem de forma direta e imediata. Longe de ser simplesmente um aparato burocrático, mais ou menos funcional, o Estado é um potente espaço de produção simbólica e cultural (Sayer, 1994; Roseberry, 1994; Joseph e Nugent, 1994; Steinmetz, 1999; Yang, 2005). Estados, em outras palavras, "definem e criam certos tipos de sujeitos e de identidades" (Roseberry, 1994, p.357). E o fazem, não apenas por meio de seus exércitos e forças policiais, mas através de "[seus] órgãos e rotinas, de [seus] procedimentos e documentos de tributação, licenciamento e registros" (Roseberry, 1994, p.357) - rotinas burocráticas monótonas e encontros de burocratas com cidadãos, os quais, segundo a antropologista Akhil Gupta, persistem "surpreendentemente subestudados, em contraste com o foco predominante sobre as maquinações de líderes estatais, mudanças nas principais políticas, mudanças de regime, ou a classe social das autoridades governamentais..." (Gupta, 2005, p.28).

Em meu trabalho atual, o Estado e suas diferentes instituições tornam-se personificados naquilo que Michael Lipsky $(1980 ; 1984)$ brilhantemente denominou "street-level bureaucrats" - servidores públicos que "interagem diretamente com os cidadãos, no desempenho de seus cargos" (1980, p.3). Fundamental para o meu argumento, é o fato de que, em interações recursivas entre os pobres e os street-level bureaucrats, o Estado "dá lições de política contribuindo para expectativas políticas futuras" (Lipsky, 1984, grifo meu), socializando "os cidadãos para expectativas de serviços do governo e de um lugar na comunidade política" (Lipsky, 1980, p.4). Assim, em sua aparente trivialidade, a prática estatal proporciona aos pobres formação política - cursos intensivos diários sobre o poder em funcionamento (Lens, 2007). 
O argumento que vou construindo aos poucos é o seguinte: longe de ser apenas uma prática negativa, uma combinação de palavras e fatos que meramente dizem às pessoas pobres que ainda não chegou a sua vez, fazer os despossuídos esperarem tem alguns potenciais "efeitos positivos, mesmo se à primeira vista são marginais" (Foucault, 1979, p. 23). O principal entre esses efeitos positivos é a fabricação cotidiana de sujeitos sabedores (e que agem segundo este saber) de que, ao lidar com burocracias estatais, devem cumprir pacientemente as exigências aparentemente arbitrárias, ambíguas e sempre mutantes do Estado. Esta é a ocasião adequada para lembrar que a raiz latina da palavra paciência, "a qualidade de ser paciente no sofrimento" de acordo com o Oxford English Dictionary, é pati - "sofrer, suportar". Nas interações recursivas com o Estado, documentadas em observações etnográficas e entrevistas, as pessoas pobres aprendem que têm de permanecer temporariamente negligenciadas, desatendidas ou postergadas. Na verdade, os pobres obedecem por falta de alternativas; mas, como estou testemunhando em meu trabalho etnográfico em curso, eles acatam silenciosamente, ainda que de má vontade, porque aprenderam, também, a ineficácia de protestar publicamente. Como revela o trabalho etnográfico comparativo em três distintos "espaços de espera", as pessoas pobres sabem (porque este conhecimento Ihes foi inculcado em reiterados encontros) que, se quiserem obter o tão necessitado "auxílio" (na forma de um bem, de um benefício social ou de um serviço), devem mostrar que são merecedoras da ajuda aguardando diligentemente; elas sabem que devem evitar criar problemas; e sabem que devem, como muitas me contaram, "continuar vindo e esperar, esperar, esperar". Em seus frequentes encontros com políticos, burocratas e autoridades, os pobres urbanos aprendem, sustento eu, a ser pacientes do Estado. Ao serem forçados repetidamente a acomodar-se e a ceder aos ditames do Estado, os pobres urbanos recebem, desse modo, uma sutil e 
geralmente não explícita lição cotidiana de subordinação política. Interpretada sob este ângulo, a espera deixa de ser um "tempo morto" e fazer as pessoas pobres esperarem transforma-se em algo mais do que mera ação "repressiva". A experiência subjetiva da espera e a prática regular de fazer os destituídos esperarem tornam-se fenômenos produtivos.

\section{Etnografia política}

Assim, são muitas as lições analíticas e substantivas que aprendi ao longo de todos esses anos de, para parafrasear Robert Park, sujar os fundiIhos das calças em muita investigação entre os mais destituídos. E muitas dessas lições poderiam virar ferramentas para outros pesquisadores que atuam em outros lugares do mundo. A troca de "votos por favores", que define o arranjo clientelista, é uma transação muito mais complexa do que parece à primeira vista; a patronagem se relaciona com a ação coletiva segundo modos que não têm sido devidamente perscrutados; a ação coletiva se relaciona com a política dominante segundo formas obscuras (e dissimuladas) que precisam ser minuciosamente examinadas; o sofrimento ambiental determina as vidas dos pobres de modos que até agora não estudamos em detalhe - assim como a espera pelo seu "Godot"*

Ao longo de anos, tenho me dedicado a um tipo de etnografia política que pretendeu avaliar criticamente as forças e limitações de conceitos centrais da sociologia tais como clientelismo e ação coletiva. Ao demonstrar a suficiência (ou insuficiência) dessas ferramentas conceituais vis-à-vis uma descrição detalhada dos processos que elas se propõem a descrever, meu trabalho tentou mostrar as virtudes e/ou os defeitos desses

\footnotetext{
* NT: Referência à peça de Samuel Beckett, "À espera de Godot", classificada como teatro do absurdo, na qual dois personagens, Vladimir e Estragon, esperam em vão e indefinidamente pela chegada de alguém chamado Godot.
} 
conceitos chave. Esta experimentação da suficiência de conceitos frente à realidade empírica identifica os riscos envolvidos na aplicação acrítica de tais conceitos e ilumina o caminho para o desenvolvimento de noções mais precisas e de teorias mais ajustadas aos dados empíricos. Embora este tipo de etnografia política raras vezes seja aplicável ao teste direto de hipóteses teóricas, ele é essencial para uma apreciação crítica da capacidade dos principais conceitos ordenadores empregados por aqueles que desejam testar teorias em contraposição a dados empíricos. Com muita frequência, devo acrescentar, esta testagem da teoria é desempenhada com base no que se poderia chamar de "fatos estilizados", descrições supersimplificadas, geradas por conceitos e noções que normalmente deixam de captar processos pontuais, microssociológicos, em funcionamento. Consequentemente, muito do trabalho macrossociológico em sociologia política repousa sobre microfundamentos conceitualmente frágeis. Concluindo, o tipo de etnografia política que empreendi (e que defendo) constitui uma ferramenta essencial para proporcionar uma base mais sólida ao fazer sociológico (tanto teórico como empírico).

Ao longo do caminho, consegui captar o valor da etnografia para observar microscopicamente os fundamentos das instituições políticas e de suas práticas de atendimento, para dissecar as complexidades e significados implícitos do cotidiano da política. Essa lição veio com uma advertência, mais bem expressa por meu então mentor, Charles Tilly, que, em resposta a um manuscrito que lhe enviei, escreveu que a etnografia política era uma:

empresa arriscada, ao mesmo tempo intensamente sociável e profundamente isoladora. Por um lado, sua busca efetiva exige estreito envolvimento com atores políticos e, portanto, o perigo de tornar-se instrumento, representante, intermediário ou cúmplice dos mesmos. Por outro lado, destacar a informação para que outros possam entendê-la depende de múltiplas traduções: de relatos contados pelos participantes políticos a relatos que os públicos irão entender, das circunstâncias locais a tópicos passíveis de reconhecimento fora da 
localidade, de explanações concretas de ações específicas a relatos nos quais quem está de fora poderá pelo menos identificar analogias com categorias de ações conhecidas.

Se a etnografia política é seu objeto, aí está um alerta.

\section{Poor people's lives and politics - the things a political ethnographer knows (and doesn't) after 15 years of fieldwork}

\section{Abstract}

Reflecting on a decade and a half of ethnographic fieldwork, this article examines the lessons learned while attempting to scrutinize the political dynamics among the urban poor. It begins with an analysis of the limitations of the concept of political clientelism to understand what really goes on when votes are "exchanged" for resources. It then studies the recursive relationship between patronage and collective action - two political phenomena typically seen as antagonistic to each other. The paper then elaborates on the notion of "the gray zone" - as the area of clandestine connections between perpetrators of violence and established political authorities. The article finishes with an examination of two themes that have been surprisingly absent in the research on the urban poor, environmental suffering and the politics of waiting.

Keywords: Political ethnography. Collective action. Clientelism. Patronage. Politics of the poors. Politics of waiting. Environmental suffering.

\section{Referências}

ABU-LUGHOD, Janet L. Race, Space, and Riots in Chicago, New York, and Los Angeles. New York: Oxford University Press, 2007.

APPADURAI, Arjun. Putting Hierarchy in its Place. Cultural Anthropology, 3, n. 1, p. 36-49, 1988.

ARIAS, Desmond. Drugs and Democracy in Rio de Janeiro. Durham: University of North Carolina Press, 2006. 
ARIAS, E. D. Trouble en Route: Drug Trafficking and Clientelism in Rio de Janeiro Shantytowns. Qualitative Sociology, 29, p. 427-445, 2006.

ASTORGA, Luis. El Siglo de las Drogas. Mexico: Plaza y Janes, 2005.

AUYERO, Javier; SWISTUN, Débora. Flammable. Environmental Suffering in an Argentine Shantytown. New York: Oxford University Press, 2009.

AUYERO, Javier. Poor People's Politics. Durham: Duke University Press, 2000.

AUYERO, Javier. Routine Politics and Collective Violence in Argentina. The Gray Zone of State Power. Cambridge: Cambridge University Press, 2007.

BODEMAN, M. Relations of Production and Class Rule: The Hidden Basis of patron-Clientage. In: WELLMAN, Barry; BERKOWITZ, Stephen D. Social Structures: a Network Approach. Cambridge: Cambridge University Press, 1988. p. 198-220.

BOURDIEU, Pierre. Outline of the Theory of Practice. Cambridge: Cambridge University Press, 1977.

BOURDIEU, Pierre. Practical Reason. California: Stanford University Press, 1998. BOURDIEU, Pierre. Pascalian Meditations. California: Stanford University Press, 2000. BRASS, Paul. Theft of an Idol. New Jersey: Princeton University Press, 1997.

BROADBENT, Jeffrey. Environmental Politics in Japan: Networks of Power and Protest. Cambridge: Cambridge University Press, 1998.

BROADBENT, Jeffrey. Movement in Context: Thick Social Networks and Environmental Mobilization in Japan. In: DIANI, M.; McADAM, D. (eds.). Social Movements and Networks: Relational Approaches to Collective Action. New York: Oxford University Press, 2003.

BRUSCO, V.; NAZARENO, M.; STOKES, S. Vote Buying in Argentina. Latin American Research Review, 39, p. 66-88. Buenos Aires: Universidad de General Sarmiento, 2004.

BURGWALD, Gerrit. Struggle of the Poor: Neighborhood Organization and Clientelist Practice in a Quito Squatter Settlement. Amsterdam: CEDLA, 1995.

COHEN, Stanley; TAYLOR, Laurie. Psychological Survival. The Experience of Long-Term Imprisonment. Middlesex: Penguin Books, 1972.

COMFORT, Megan. Doing Time Together. Chicago: University of Chicago Press, 2008.

DAS, Veena (Ed.). Mirrors of Violence. Communities, Riots, and Survivors in South Asia Oxford: Oxford University Press, 1990.

DE JESUS, Carolina. Child of the Dark. The Diary of Carolina Maria de Jesus. New York: Signet, 2003. 
DIANI, M.; McADAM, D. Social Movements and Networks: Relational Approaches to Collective Action New York: Oxford University Press, 2003.

DURKHEIM, Emile. The Elementary Forms of the Religious Life. New York: The Free Press, 1965.

EMIRBAYER, Mustafa; GOODWIN, Jeff. Network analysis, culture, and the problem of agency. The American Journal of Sociology, Vol. 99, n 6, p. 1411-1454, 1994.

ENGELS, Friedrich. The Condition of the Working-Class in England. London: Lawrence \& Wishart, 1973 [1844].

EVANS, Peter (editor). Livable Cities? Urban Struggles for Livelihood and Sustainability. Berkeley: University of California Press, 2002.

FARMER, Paul. Pathologies of Power. Health, Human Rigths, and the New War on the Poor. California: University of California Press, 2003.

FLAHERTY, Michael. A Watched Pot. How We Experience Time. New York: New York University Press, 1999.

FLAHERTY, Michael. The Textures of Time. Agency and Temporal Experience. Philadelphia: Temple University Press, 2010.

FLAHERTY, Michael; FREIDIN, Betina; SAUTU, Ruth. Variation in the Perceived Passage of Time: a Cross-National Study. Social Psychology Quarterly, 68, p. 400-410, 2005.

FOUCAULT, Michel. Discipline and Punish. New York: Vintage, 1979.

GAY, Robert. Community Organization and Clientelist Politics in Contemporary Brazil: a case study from suburban Rio de Janeiro. International Journal of Urban and Regional Research, 14, p. 648-666, 1990.

GAY, Robert. Popular Organization and Democracy in Rio de Janeiro. A Tale of Two Favelas. Philadelphia: Temple University Press, 1994.

GEERTZ, Clifford. The Interpretation of Cultures. New York: Basic Books, 1973. GIDDENS, Anthony. The Constitution of Society. New York: Polity Press, 1986.

GOLDSTEIN, Donna. Laughter Out of Place. Race, Class, and Sexuality in a Rio Shantytown. Berkeley, CA: University of California Press, 2003.

GONZÁLEZ DE LA ROCHA, Mercedes et al. From the Marginality of the 1960s to the 'New Poverty' of Today: a LARR Research Forum." Latin American Research Review, 39 (1), p. 184-203, 2004.

GUNST, Laurie. Born Fi' Dead: a Journey Through the Yardie Posse Underworld. New York: Canongate Books, 1995. 
GUNST, Laurie. Born Fi'Dead: A Journey Through the Jamaican Posse Underworld. Henry Holt \& Co, 1995.

GUPTA, Akhil. Blurred Boundaries: The Discourse of Corruption, the Cultur of Politics, and the Imagined State. American Ethnologist, 22 (2), p. 375-402, 1995.

GUPTA, Akhil. Narratives of Corruption: Anthropological and Fictional Accounts of the Indian State. Ethnography, 6 (1), p. 5-34, 2005.

GUTERBOCK, Thomas. M. Machine Politics in Transition: Party and Community in Chicago: Chicago. University Of Chicago Press, 1980.

HANEY, Lynne. Homeboys, Babies, and Men in Suits: The State and the Reproduction of Male Dominance. American Sociological Review, 61 (5), p. 759-778, 1996.

HELLER, Patrick; EVANS, Peter. Taking Tilly South: Durable Inequalities, Democratic Contestation, and Citizenship in the Southern Metropolis. Theory and Society, 39, p. 433-450, 2010.

HELMKE, Gretchen; LEVITSKY, Stephen (eds.). Informal Institutions and Comparative Politics. Perspectives in Politics. 2, p. 725-740, 2004.

HOCHSCHILD, A. The Time Bind. New York: Holt, 2001.

HOCHSTETLER, Kathryn; KECK, Margaret. The Greening of Brazil. Environmental Activism in State and Society. Durham: Duke University Press, 2007.

HOFFMAN, Kelly; CENTENO, Miguel Angel. The Lopsided Continent: Inequality in Latin America. Annual Review of Sociology, 29, p. 363-90, 2003.

HOLZNER, Claudio. The End of Clientelism? Strong and Weak Networks in a Mexican Squatter Movement. Mobilization, 9 (3), p. 223-240, 2004.

JACOBS, Jerry; KATHLEEN, Gerson. The Time Divide. Cambridge: Harvard University Press, 2005.

JESSOP, Bob. Narrating the Future of the National Economy and the National State: Remarks on Remapping Regulation and Reinventing Governance. In: STEINMETZ, George (editor). State/Culture. State Formation after the Cultural Turn. Ithaca, NY: Cornell University Press, 1999. p. 378-406.

JOSEPH, Gilbert; NUGENT, Daniel (Eds.). Everyday Forms of State Formation. Durham: Duke University Press, 1994.

KAKAR, Sudhir. The Colors of Violence. Cultural Identities, Religion, and Conflict. Chicago: The University of Chicago Press, 1996.

KALYVAS, Stathis. N. 'The Ontology of 'Political Violence': Action and Identity in Civil Wars. Perspectives on Politics, 1, p. 475-494, 2003. 
KITSCHELT, Herbert; WILKINSON, Steven I. (eds.). 2007. Patrons, Clients and Policies: Patterns of Democratic Accountability and Political Competition. Cambridge: Cambridge University Press, 2007.

KNOKE, David. Political Networks: The Structural Perspective. Cambridge: Cambridge University Press, 1990.

LAZAR, Sian. El Alto, Rebel City: Self and Citizenship in Andean Bolivia. Durham: Duke University Press, 2008.

LEMARCHAND, Rene. Comparative political clientelism: structure, process and optic. In: EISENTADT, S. N.; LEMARCHAND, R. (eds.). Political Clientelism, Patronage and Development. London: Sage, p. 7-32, 1981.

LEMOS, Maria Carmen de Mello. The Politics of Pollution Control in Brazil: State Actors and Social Movements Cleaning Up Cubatao. World Development, Vol.26, No.1, p. 75-87, 1998.

LENS, Vicki. Administrative Justice in Public Welfare Bureaucracies. When Citizens (Don't) Complain. Administration and Society. 39(3), p. 382-408, 2007.

LEVINE, Robert. A Geography of Time. New York: Basic Books, 1997.

LEVITSKY, Steve; WAY, Lucan A. Linkage, Leverage and the Post-Communist Divide. East European Politics and Societies, 27, No. 21: 48-66, 2007.

LEVITSKY, Steve. Transforming Labor-Based Parties in Latin America: Argentine Peronism in Comparative Perspective. Cambridge: Cambridge University Press, 2003.

LIPSKY, Michael. Street Level Bureaucracy. New York: Russel Sage Foundation, 1980.

LIPSKY, Michael. Bureaucratic Disentitlement in Social Welfare Programs. The Social Service Review 58(1), p. 3-27, 1984.

LUKES, Steven. Power: a Radical View. New York: Palgrave, 2005.

MANN, Leon. Queue Culture: The Waiting Line as a Social System. American Journal of Sociology, 75, p. 340-354, 1969.

MARX, Karl. Capital, Vol.1. New York: New World, 1887.

MASSEY, Doreen. Space, Place, and Gender. Minneapolis: University of Minnesota Press, 1994.

McADAM, Doug; FERNANDEZ, Roberto. Microstructural Bases of Recruitment to Social Movements. Research in Social Movements, Conflict and Change, 12, p. 1-33. 1990.

McADAM, Doug; TARROW, Sidney; TILLY, Charles. Dynamics of Contention. Cambridge e New York: Cambridge University Press, 2001. 
McADAM, Doug; TARROW, Sidney; TILLY, Charles. Methods for Measuring Mechanisms of Contention. Qualitative Sociology, Volume 31, Number 4, p. 307-331, 2008.

MCADAM, Doug. Political Process and the Development of Black Insurgency, 1930-1970. Chicago: University Of Chicago Press, 1982.

MERTON, Robert K. Social Theory and Social Structure. The Free Press of Glencoe, 1949.

MISCHE, Ann. Cross-talk in Movements: Reconceiving the Culture-Network Link. In: DIANI, M.; McADAM, D. (eds.). Social Movements and Networks: Relational Approaches to Collective Action. Oxford: Oxford University Press, 2003.

MORRIS, Aldon. The Origins of the Civil Rights Movement: Black Communities Organizing for Change. Free Press, 1984.

MUNN, Nancy. The Cultural Anthropology of Time: A Critical Essay. Annual Review of Anthropology, 21, p. 91-123, 1992.

NICHTER, Simeon. Vote Buying or Turnout Buying? Machine Politics and the Secret Ballot. American Political Science Review, 102 (1), p. 19-31, 2008.

O'BRIEN, Edna. Waiting. In: KINCAID, J.; ATAWAN, R. (Eds.). The Best American Essays. Boston: Houghton Mifflin Company, 1995.

O'DONNELL, Guillermo. Delegative Democracy? Kellogg Working Paper no. 172. Notre Dame, Ind.: Kellogg Institute for International Studies, University of Notre Dame, 1992.

OLIVER, Pamela. "If You Don't Do it, Nobody Else Will": Active and Token Contributors to Local Collective Action. American Sociological Review, Vol. 49, No. 5, p. 601-610, 1984.

ORTNER, Sherry. Resistance and the Problem of Ethnographic Refusal. Comparative Studies in Society and History, 37(1), p. 173-193, 1995.

OSA, M. Creating Solidarity: the Religious Foundations of the Polish Social Movement. East European Politics and Societies, 11, p. 339-356, 1997.

PALEY, Julia. Marketing Democracy. Power and Social Movements in Post-Dictarship Chile. Berkeley: California University Press, 2001.

PASSY, Florence. Social Networks Matter. But How? In: DIANI, M.; McADAM, D. (eds.). Social Movements and Networks: Relational Approaches to Collective Action Oxford: Oxford University Press, 2003.

PATTERSON, Orlando. The Roots of Conflict in Jamaica. The New York Times, January 23. Online edition. Accessed May 1, 2001.

PEZZOLI, Keith. Human Settlements and Planning for Ecological Sustainability: The Case of Mexico City. Cambridge, Mass: The MIT Press, 2000. 
PITT-RIVERS, Julian Alfred. The people of the Sierra. New York: Criterion Books, 1954.

PIVEN, Frances; CLOWARD, Richard. Regulating the Poor: The Functions of Public Welfare. New York: Vintage, 1971.

PURSER, Gretchen. Waiting for Work: An Ethnography of a Day Labor Agency. Institute for the Study of Social Change, ISSC Fellows Working Papers, eRepository. California Digital Library, 2006.

QUIRÓS, Julieta. Piqueteros y peronistas en la lucha del Gran Buenos Aires. Por una visión no instrumental de la política popular. Cuadernos de Antropología Social, № 27, p. 113-131, 2008.

REDKO, Cristina; RAPP, Richard; CARLSON, Robert. Waiting Time as a Barrier to Treatment Entry: Perceptions of Substance Abusers. Journal of Drug Issues, 22, p. 831-852, 2006.

ROCK, David. Machine Politics in Buenos Aires and the Argentine Radical Party, 1912-1930. Journal of Latin American Studies, 4, p. 233-56, 1972.

ROCK, David. Politics in Argentina: The Rise and Fall of Radicalism, 1890-1930. Cambridge: Cambridge University Press, 1975.

ROLDÁN, Mary. Blood and Fire: La Violencia in Antioquia, Colombia, 19461953. Durham: Duke University Press, 2002.

RONIGER, Luis; GÜNES-AYATA, Ayse. Democracy, Clientelism, and Civil Society. London: Lynne Rienner Publishers, 1994.

RONIGER, Luis. Hierarchy and trust in modern Mexico and Brazil. New York: Praeger, 1990.

ROSEBERRY, William. Hegemony and the Language of Contention. In: JOSEPH, Gilbert M.; NUGENT, Daniel (eds.). Everyday Forms of State Formation: Revolution and the Negotiation of Rule in Modern Mexico. Durham: Duke University Press, 1994.

ROTH, Julius. Timetables: Structuring the Passage of Time in Hospital Treatment and Other Careers. Indianapolis: Bobbs-Merrill, 1963.

RUTTEN, Rosanne. Losing Face in Philippine Labor Confrontations: How Shame May Inhibit Worker Activism. In: JOSEPH, Lauren; MAHLER, Matthew; AUYERO, Javier. (Eds.). New Perspectives in Political Ethnography. New York: Springer, 2007.

SAYER, Derek. Everyday Forms of State Formation: Some Dissident Remarks on 'Hegemony.' In: JOSEPH, Gilbert M.; NUGENT, Daniel (eds.). Everyday Forms of State Formation: Revolution and the Negotiation of Rule in Modern Mexico. Durham: Duke University Press, 1994.

SCHEPER-HUGHES, Nancy. Death Without Weeping. California: California University Press, 1994. 
SCHMIDT, Steffen. W. La Violencia Revisited: The Clientelist Bases of Political Violence in Colombia. Journal of Latin American Studies, 6, p. 97-111, 1974.

SCHUTZ, Alfred. The Problem of Social Reality. Collected Papers 1. The Hague: Martinus Nijhoff, 1964.

SCHWARTZ, Barry. Queuing and Waiting. Studies in the Social Organization of Access and Delay. Chicago: The University of Chicago Press, 1975.

SCHWARTZ, Barry. Waiting, Exchange, and Power: The Distribution of Time in Social Systems. American Journal of Sociology, 79, p. 841-870, 1974.

SCHWEIZER, Howard. On Waiting. London: Routledge, 2008.

SCOTT, J. C.; KERKVLIET, B. J. How Traditional Rural Patrons Lose Legitimacy (in Southeast Asia). In: Friends, Followers, and Factions: a Reader in Political Clientelism, edited by S. Schmidt. Berkeley, CA: University of California Press. 1977.

SCOTT, James C. Political Clientelism: a Bibliographical Essay. In: SCHMIDT, Steffen W.; GUASTI, Laura; LANDÉ, Carl; SCOTT, James C. Friends, Followers and Factions: a Reader in Political Clientelism. Los Angeles: University of California Press. 1977.

SECOR, Anna. Between Longing and Despair: State, Space and Subjectivity in Turkey. Environment and Planning D: Society and Space, 25 (1), p. 33-52, 2007.

SILVERMAN, Sydel. Patronage and Community-Nation Relationships in Central Italy. Ethnology, 4. p. 172-189, 1965.

SIMMEL, Georg. On Individuality and Social Forms. Chicago: University of Chicago Press, 1971.

SOROKIN, Pitirim; MERTON, Robert. Social Time: a Methodological and Functional Analysis. American Journal of Sociology, 42, p. 615-29, 1937.

STEINMETZ, George. Introduction: Culture and the State. In: STEINMETZ, George (editor). State/Culture. State Formation after the Cultural Turn. Ithaca, NY: Cornell University Press,1999. p. 1-50.

STOKES, Susan. Perverse Accountability: A Formal Model of Machine Politics with Evidence from Argentina. American Political Science Review, 99 (3), p. 315-325, 2005.

SVAMPA, Maristella; PEREYRA, Sebastián. Entre la ruta y el barrio: la experiencia de las organizaciones piqueteras. Buenos Aires: Editorial Biblos, 2003.

TARROW, Sidney. The People's Two Rhythms: Charles Tilly and the Study of Contentious Politics. Comparative Studies in Society and History, 38, p. 586-600, 1996.

TAYLOR, Verta; WHITTIER, Nancy. Analytical Approaches to Social Movement Culture: The Culture of the Women's Movement. In: JOHNSTON, Hank; KLANDERMANS, Bert (eds). Social Movements and Culture. Minneapolis: University of Minnesota Press, 1995. 
THOMPSON, Edward. P. Customs in Common. New York: The New Press, 1993. THOMPSON, Jeffery; BUNDERSON, Stuart. Work-Nonwork Conflict and the Phenomenology of Time. Beyond the Balance Metaphor. Work and Occupations, 28 (1), p. 17-39, 2001.

TILLY, Charles; TARROW, Sidney. Contentious politics. Paradigm Publishers: Boulder, 2007.

TILLY, Charles. The Contentious French. Cambridge: Harvard University Press, 1986.

TILLY, Charles. To Explain Political Processes. The American Journal of Sociology, vol.100, n.6, p. 1594-1610, 1995.

TILLY, Charles. Durable Inequality. Berkeley: California University Press, 1998.

TILLY, Charles. The Politics of Collective Violence. New York: Cambridge University Press, 2003.

TILLY, Charles. Regimes and Repertoires. Chicago: Chicago University Press, 2006.

TILLY, Charles. Democracy. New York: Cambridge University Press, 2007.

TOSONI, Magdalena. Notas sobre el clientelismo político en la ciudad de México.

Perfiles Latinoamericanos, 29, p. 47-69, 2007.

WALSH, E. J. Resource Mobilization and Citizen Protest in Communities around Three Mile Island. Social Problems, 29, p. 1-21, 1981.

WILKINSON, Steven. Votes and Violence. Electoral Competition and Ethnic Riots in India. Cambridge: Cambridge University Press, 2004.

WILKINSON, Steven. 2007. Explaining changing patterns of party-voter linkages in India. In: KITSCHELT, H.; WILKINSON, S. Patrons, Clients, and Policies: Patterns of Democratic Accountability and Political Competition. Cambridge: Cambridge University Press, 2007. p. 110-140.

WILLIS, Paul. Learning to Labor. New York: Columbia University Press, 1977.

YANG, Shu-Yuan. Imagining the State. An Ethnographic Study. Ethnography, 6(4), p. 487-516, 2005.

YOUNG, Gerardo. La Trama Política de los Saqueos. Clarín Digital, December 19, 2002.

ZERUBAVEL, Eviatar. Patterns of Time in Hospital Life. Chicago: The University of Chicago Press, 1979. 